\title{
Preliminary Free Radical Scavenging, Brine Shrimp Lethality, Antimicrobial and Thrombolytic Activities of Aganosma dichotoma (Roth) K. Schum.
}

\author{
Sanjoy Chandra Dey ${ }^{1}$, Mohammd Firoz Khan ${ }^{1}$, Mohammad S. Rahman ${ }^{2}$ and \\ Mohammad A. Rashid ${ }^{2}$ \\ ${ }^{1}$ Department of Pharmacy, State University of Bangladesh, Dhaka- 1205, Bangladesh \\ ${ }^{2}$ Phytochemical Research Laboratory, Department of Pharmaceutical Chemistry, University of Dhaka, \\ Dhaka- 1000, Bangladesh
}

Received: June 24, 2014;

Accepted: July 20, 2014;

Published (Web): July 23, 2014

\begin{abstract}
Bangladesh is a good repository of natural products. Numerous plants are available to facilitate the traditional treatments. Proper scientific evaluations are essential to explore the plant derived drugs. With this view, the crude methanol extract of leaves of Aganosma dichotoma (Roth) K. Schum. and its Kupchan fractions were screened for free radical scavenging, brine shrimp lethality, antimicrobial and thrombolytic activities. Among all extractives, the chloroform soluble fraction demonstrated the highest free radical scavenging activity with $\mathrm{IC}_{50}$ value $18.21 \mu \mathrm{g} / \mathrm{ml}$. Moreover, the chloroform soluble fraction showed significant brine shrimp lethality having $\mathrm{LC}_{50}$ value of $3.98 \mu \mathrm{g} / \mathrm{ml}$. On the other hand, the petroleum ether, carbon tetrachloride and chloroform soluble materials revealed mild to moderate antimicrobial activity with the zone of inhibition ranging from 7 to $14 \mathrm{~mm}$. In the thrombolytic assay, the carbon tetrachloride soluble partitionate showed the highest clot lysis (30.48\%). This is the first report of the comprehensive investigations of different extractives of A. dichotoma for the abovementioned bioassays.
\end{abstract}

Key words: Aganosma dichotoma, Apocynaceae, free radical scavenging, antioxidant, cytotoxic, antimicrobial, thrombolytic

\section{Introduction}

Natural products have earned an admirable place in drug discovery. Screening of plants focusing on bioactivities is essential for exploring the desired drug molecules (Hung et al., 2012; Newman and Cragg, 2012). Free radicals are considered as notorious oxidizing elements to promote ageing, lipid peroxidation, inflammation and other pathologies. Plants are good sources of antioxidants (Flora, 2007; Pham-Huy et al., 2008). Brine shrimp lethality bioassay is well accepted by the natural product scientists as a bench-top tool to find out bioactive elements (Meyer et al., 1982; Rahman et al., 2008a). Besides, secondary metabolites of plants are worthy to screen out for searching anti-infective agents. There are the life saving elements available in market but drug-resistance issue promotes the need for new antimicrobials (Drago et al., 2014; Gonzalez and Cortes, 2014). Thrombus formation may lead to death by worsening the cardiovascular situation. Better drug is required to overcome limitations of the currently available drugs (Kline, 1990; Prasad et al., 2006).

The plant A. dichotoma (Roth) K. Schum. (FamilyApocynaceae, Bengali Name- Gandhomalati) is a large climber. It has a very stout stem and milky latex. Its leaves are 10-12.5 cm long, coriaceous, ovate or elliptic, acute or obtuse. The plant is grown all over Bangladesh (Patel et al., 1972; Banglapedia, 2012). It is used as antiseptic, anthelmintic, psychoactive and emetic. Previous phytochemical investigations on A. dichotoma led to the isolation of quercetin, rutin, kaempferol and phenolic acids (Khare, 2007; Sandhya et al., 2010; Subramanian et al., 2014).

The present study has been undertaken as part of our regular research (Ara et al., 2006; Begum et al., 2010; Rahman et al., 2011) and we, herein, report the comprehensive studies of free radical scavenging, brine shrimp lethality, antimicrobial and thrombolytic activities of the leaves of $A$. dichotoma for the first time. 


\section{Materials and Methods}

Plant materials: The leaves of $A$. dichotoma were collected on June, 2013 from Sylhet, Bangladesh and a voucher specimen (DACB accession no. 39645) has been deposited at Bangladesh National Herbarium, Mirpur, Dhaka for future reference.

Extraction and fractionation: The collected plant parts were sun dried for several days and then oven dried for 24 hours at $40^{\circ} \mathrm{C}$ to facilitate grinding. The powdered leaves $(650 \mathrm{~g})$ of $A$. dichotoma was extracted with $1.8 \mathrm{~L}$ methanol for 7 days and then filtered through a cotton plug followed by whatman filter paper number 1 . The extract was then concentrated by using a rotary evaporator at reduced temperature $\left(40-45^{\circ} \mathrm{C}\right)$ and pressure. The concentrated methanol extract $(5 \mathrm{~g})$ was fractionated by modified Kupchan method (VanWagenen et al., 1993) and the resultant partitionates i.e., petroleum ether, carbon tetrachloride, chloroform and aqueous soluble materials were used for different biological screenings.

Antioxidant activity: The free radical scavenging activity of the plant extractives was determined on the stable radical produced by 1,1-diphenyl-2-picrylhydrazyl (DPPH) (Parvin et al., 2009; Chowdhury et al., 2010).

Brine shrimp lethality: This technique (Meyer et al., 1982; Rahman et al., 2008a) was applied for the determination of general toxic property of the plant extractives indicating bioactive materials using Artemia salina in a 1-day in vivo assay. Vincristine sulfate was used as positive control.

Antimicrobial activity: The antimicrobial activity of the extractives was determined by the disc diffusion method (Bauer et al., 1966; Rahman et al., 2008b) against 5 gram positive bacteria and 8 gram negative bacteria (Table 4). The organisms were collected as pure cultures from the Institute of Nutrition and Food Sciences (INFS),
University of Dhaka. Standard disc of Ciprofloxacin (5 $\mu \mathrm{g} / \mathrm{disc}$ ) was used as standard.

Thrombolytic activity: The in vitro thrombolytic assay was performed by the method developed by Prasad et al., 2006. In the present assay, human venous blood was used.

Statistical Analysis: Three replicates of each sample were used and the values are reported as mean \pm standard deviation (SD).

\section{Results and Discussion}

The different partitionates of methanol extract of $A$. dichotoma were tested for free radical scavenging activity. The $\mathrm{IC}_{50}$ values of the extractives were found in the range of $18.21 \mu \mathrm{g} / \mathrm{ml}$ to $81.12 \mu \mathrm{g} / \mathrm{ml}$. The chloroform soluble fraction showed highest $\left(\mathrm{IC}_{50}=18.21\right)$ free radical scavenging activity (Table 1).

Table 1. $\mathrm{IC}_{50}$ values of standard and different partitionates of $A$. dichotoma in DPPH assay.

\begin{tabular}{lc}
\hline Samples & $\mathrm{IC}_{50}(\mu \mathrm{g} / \mathrm{ml})$ \\
\hline Tert- butyl-1-hydroxytoluene (standard) & $27.23 \pm 0.44$ \\
Crude methanol extract & $49.34 \pm 0.35$ \\
Petroleum ether soluble fraction & $81.12 \pm 0.38$ \\
Carbon tetrachloride soluble fraction & $19.99 \pm 0.51$ \\
Chloroform soluble fraction & $18.21 \pm 0.34$ \\
Aqueous fraction & $40.50 \pm 0.47$ \\
\hline
\end{tabular}

In the brine shrimp lethality screening, median lethal concentration $\left(\mathrm{LC}_{50}\right)$ of the test samples after 24 hours was obtained by a plot of percentage of the shrimps killed against the logarithm of the sample concentration and the best-fit line was obtained from the graph by means of regression analysis. The chloroform soluble materials exhibited highest lethality with $\mathrm{LC}_{50}$ value of $3.98 \mu \mathrm{g} / \mathrm{ml}$ (Table 2).

Table 2. $\mathrm{LC}_{50}$ values of standard and different partitionates of $\boldsymbol{A}$. dichotoma in brine shrimp lethality bioassay.

\begin{tabular}{lccc}
\hline Samples & Regression line & $\mathrm{R}^{2}$ & $\mathrm{LC}_{50}(\mu \mathrm{g} / \mathrm{ml})$ \\
\hline Vincristine sulfate (standard) & $\mathrm{y}=30.8 \mathrm{x}+60.64$ & 0.96 & $0.47 \pm 0.11$ \\
Crude methanol extract & $\mathrm{y}=17.11 \mathrm{x}-6.347$ & 0.88 & $1964.36 \pm 0.64$ \\
Petroleum ether soluble fraction & $\mathrm{y}=21.74 \mathrm{x}-11.12$ & 0.87 & $647.75 \pm 0.52$ \\
Carbon tetrachloride soluble fraction & $\mathrm{y}=29.79 \mathrm{x}-15.16$ & 0.93 & $153.93 \pm 0.47$ \\
Chloroform soluble fraction & $\mathrm{y}=27.78 \mathrm{x}+33.34$ & 0.91 & $3.98 \pm 0.32$ \\
\hline
\end{tabular}


Table 3. Antimicrobial activity of $A$. dichotoma extractives at $400 \mu \mathrm{g} / \mathrm{disc}$.

\begin{tabular}{lccccc}
\hline Test microorganisms & \multicolumn{5}{c}{ Diameter of zone of inhibition (mm) } \\
\cline { 2 - 5 } & ME & PE & CT & CL & CF \\
\hline Gram positive bacteria & & & & & \\
Bacillus sereus & - & - & - & - & $44 \pm 0.23$ \\
B. megaterium & - & - & $14 \pm 0.21$ & $12 \pm 0.41$ & $44 \pm 0.34$ \\
B. subtilis & - & $10 \pm 0.34$ & $10 \pm 0.22$ & - & $44 \pm 0.21$ \\
Staphylococcus aureus & - & $10 \pm 0.20$ & $12 \pm 0.30$ & $12 \pm 0.46$ & $46 \pm 0.33$ \\
Sarcina lutea & - & - & $7 \pm 0.24$ & $12 \pm 0.12$ & $46 \pm 0.20$ \\
Gram negative Bacteria & & & & & \\
Escherichia coli & - & $10 \pm 0.51$ & $8 \pm 0.35$ & $10 \pm 0.34$ & $45 \pm 0.12$ \\
Pseudomonas aeruginosa & - & - & $8 \pm 0.54$ & $9 \pm 0.23$ & $46 \pm 0.10$ \\
Salmonella Paratyphi & - & $9 \pm 0.19$ & - & - & $45 \pm 0.21$ \\
S. Typhi & - & - & $12 \pm 0.21$ & $12 \pm 0.54$ & $45 \pm 0.40$ \\
Shigella dysenteriae & - & - & $8 \pm 0.40$ & $12 \pm 0.41$ & $48 \pm 0.04$ \\
S. boydii & - & - & - & - & $46 \pm 0.42$ \\
Vibrio mimicus & - & $12 \pm 0.23$ & $12 \pm 0.041$ & $13 \pm 0.22$ & $45 \pm 0.21$ \\
V. parahemolyticus & - & $10 \pm 0.25$ & $10 \pm 0.32$ & $12 \pm 0.42$ & $45 \pm 0.21$ \\
\hline
\end{tabular}

'-' indicates no response, ME- crude methanol extract, PE- petroleum ether soluble fraction, CT- carbon tetrachloride soluble fraction, CL- chloroform soluble fraction, CF- ciprofloxacin $(5 \mu \mathrm{g} / \mathrm{disc})$

The crude extract and its different partitionates were subjected to antimicrobial screening at $400 \mu \mathrm{g} /$ disc. The petroleum ether, carbon tetrachloride and chloroform soluble fractions displayed weak to moderate antimicrobial activity with the zone of inhibition ranging from 7 to $14 \mathrm{~mm}$ (Table 3).

In the thrombolytic assay, the carbon tetrachloride soluble fraction revealed the highest thrombolytic activity (30.48\%) followed by chloroform (27.09\%) and aqueous (26.17\%) soluble fractions (Table 4).

Table 4. Thrombolytic activity (in terms of \% clot lysis) of $A$. dichotoma.

\begin{tabular}{ll}
\hline Sample & \% of clot lysis \\
\hline Water (Blank) & $1.81 \pm 0.38$ \\
Streptokinase (Standard) & $65.27 \pm 0.51$ \\
Crude methanol extract & $12.00 \pm 0.74$ \\
Petroleum ether soluble fraction & $11.26 \pm 0.42$ \\
Carbon tetrachloride soluble fraction & $30.48 \pm 0.32$ \\
Chloroform soluble fraction & $27.09 \pm 0.37$ \\
Aqueous fraction & $26.17 \pm 0.43$ \\
\hline
\end{tabular}

Bangladesh is located in tropical zone facilitating the growth of numerous medicinal plants. The current experiment was designed to screen the free radical scavenging, brine shrimp lethality, antimicrobial and thrombolytic activities of $A$. dichotoma growing in
Bangladesh. The experimental data of the assays have been summarized in Tables 1 to 4 .

Excess free radicals and oxidants produce oxidative stress causing injury to cellular proteins, lipids, lipoproteins and deoxyribonucleic acid. If not controlled, oxidative stress can induce a variety of chronic and degenerative diseases, aging process, trauma, inflammatory damages etc. (Arrigoni-Martelli, 1985; Hewitt et al., 1987; Hamvas et al., 1992). In the current study, A. dichotoma significantly scavenged the free radicals generated by DPPH to demonstrate its antioxidant activity (Table 1).

The bioactivities of plants are always generated from secondary metabolites. The lethality of brine shrimp due to toxicity is considered as an indicator of the presence of bioactive compounds (Meyer et al., 1982; McLaughlin et al., 1998). This current assay showed the presence bioactive natural compounds in the test samples of $A$. dichotoma (Table 2).

Thrombus formation in the circulatory system causes vascular blockage leading to death. Currently used thrombolytic agents that include tissue plasminogen activator, urokinase, streptokinase etc. are used but still associated with risk of hemorrhage, anaphylactic reaction and lack specificity. So, attempts are still ongoing around the world to develop improved thrombolytic agents 
(Wilson and Chaikof, 2008; Rodriguez et al., 2012; Sikder et al., 2012). With this view, this investigation was done on $A$. dichotoma. The carbon tetrachloride, chloroform and aqueous fractions displayed moderate thrombolytic activity (Table 4).

\section{Conclusion}

A. dichotoma has many bioactive secondary metabolites as evident from brine shrimp lethality bioassay. Besides, it can provide antioxidants and thrombolytic agents. In addition, moderate antimicrobial and thrombolytic constituents can be expected from the extractives of this plant. Further phytochemical investigation is required to isolate the bioactive molecules from this plant.

\section{References}

Ara, K., Rahman, A. H., Hasan, C. M., Iskander, M. N., Asakawa, Y., Quang, D. N. and Rashid, M. A. 2006. Macrocyclic diarylheptanoids from Garuga pinnata. Phytochemistry 67, 2659-2662.

Arrigoni-Martelli, E. 1985. Pharmacology of free radical scavenging in inflammation. Int. J. Tissue React. 7, 513519.

Banglapedia. 2012. Garden Flowers. National Encyclopedia of Bangladesh (online edition). http://www.banglapedia. org/HT/G_0040.htm

Bauer, A. W., Kirby, W. M., Sherris, J. C. and Turck, M. 1966. Antibiotic susceptibility testing by a standardized single disk method. Am. J. Clin. Pathol. 45, 493-496.

Begum, R., Rahman, M. S., Chowdhury, S., Rahman, M. M., Gibbons, S. and Rashid, M. A. 2010. A new 7-oxygenated coumarin from Clausena suffruticosa. Fitoterapia 81, 656658.

Chowdhury, A., Alam, M. A., Rahman, M. S., Hassan, M. A. and Rashid, M. A. 2010. Antioxidant, antimicrobial and cytotoxic activities of Corypha taliera Roxb. Latin Am. J. Pharm. 29, 1231-1234.

Drago, L., De Vecchi, E., Cappelletti, L., Mattina, R., Vassena, C. and Romano, C. L. 2014. Role and antimicrobial resistance of Staphylococci involved in prosthetic joint infections. Int. J. Artif. Organs 37, 414-421.

Flora, S. J. 2007. Role of free radicals and antioxidants in health and disease. Cell. Mol. Biol. (Noisy-le-grand). 53, 1-2.

Gonzalez, L. and Cortes, J. A. 2014. Systematic review of antimicrobial resistance in Enterobacteriaceae isolates from Colombian hospitals. Biomedica 34, 180-197.
Hamvas, A., Palazzo, R., Kaiser, L., Cooper, J., Shuman, T., Velazquez, M., Freeman, B. and Schuster, D. P. 1992. Inflammation and oxygen free radical formation during pulmonary ischemia-reperfusion injury. J. Appl. Physiol. 72, 621-628.

Hewitt, S. D., Lunec, J., Morris, C. J. and Blake, D. R. 1987. Effect of free radical altered $\operatorname{IgG}$ on allergic inflammation. Ann. Rheum. Dis. 46, 866-874.

Hung, H. Y., Qian, K., Morris-Natschke, S. L., Hsu, C. S. and Lee, K. H. 2012. Recent discovery of plant-derived antidiabetic natural products. Nat. Prod. Rep. 29, 580-606.

Khare, C. P. 2007. Indian Medicinal Plants: An Illustrated Dictionary. Springer Science, LLC, New York, USA., p. 24.

Kline, E. M. 1990. Pharmacologic review of thrombolytic agents. Crit. Care Nurs. Clin. North Am. 2, 613-627.

McLaughlin, J. L., Rogers, L. L. and Anderson, J. E. 1998. The use of biological assays to evaluate botanicals. Drug Inf. J. 32, 513-524.

Meyer, B. N., Ferrigni, N. R., Putnam, J. E., Jacobsen, L. B., Nichols, D. E. and McLaughlin, J. L. 1982. Brine shrimp: a convenient general bioassay for active plant constituents. Planta Med. 45, 31-34.

Newman, D. J. and Cragg, G. M. 2012. Natural products as sources of new drugs over the 30 years from 1981 to 2010 . J. Nat. Prod. 75, 311-335.

Parvin, M. N., Rahman, M. S., Islam, M. S. and Rashid, M. A. 2009. Chemical and biological investigations of Dillenia indica Linn. Bangladesh J. Pharmacol. 4, 122-125.

Patel, J. D., Kothari, I. L. and Pathan, M. A. 1972. Stomatal Features in the Leaf of Aganosma dichotoma (Roth) K. Schum. Ann. Bot. 36, 849-856.

Pham-Huy, L. A., He, H. and Pham-Huy, C. 2008. Free radicals, antioxidants in disease and health. Int. J. Biomed. Sci. 4, 89-96.

Prasad, S., Kashyap, R. S., Deopujari, J. Y., Purohit, H. J., Taori, G. M. and Daginawala, H. F. 2006. Development of an in vitro model to study clot lysis activity of thrombolytic drugs. Thromb. J. 4, 14.

Rahman, M. S., Begum, B., Chowdhury, R., Rahman, K. M. and Rashid, M. A. 2008a. Preliminary cytotoxicity screening of some medicinal plants of Bangladesh. Dhaka Univ. J. Pharm. Sci. 7, 47-52.

Rahman, M. S., Rahman, M. Z., Begum, B., Chowdhury, R., Islam, S. N. and Rashid, M. A. 2011. Antidiabetic principle from Eclipta Prostrata. Latin Am. J. Pharm. 30, 1656-1660.

Rahman, M. S., Rahman, M. Z., Wahab, M. A., Chowdhury, R. and M.A., R. 2008b. Antimicrobial activity of some indigenous plants of Bangladesh. Dhaka Univ. J. Pharm. Sci. 7, 23-26. 
Rodriguez, A. L., Wojcik, B. M., Wrobleski, S. K., Myers, D. D., Jr., Wakefield, T. W. and Diaz, J. A. 2012. Statins, inflammation and deep vein thrombosis: a systematic review. J. Thromb. Thrombolysis 33, 371-382.

Sandhya, S., Vinod, K. R. and Kumar, S. 2010. Herbs Used for Brain Disorders. Hygeia. J. D. Med. 2, 38-45.

Sikder, M. A. A., Kaisar, M. A., Rashid, M. A., Millat, M. S. and Sultana, A. 2012. In vitro Membrane Stabilizing Activity, Total Phenolic Content, Cytotoxic, Thrombolytic and Antimicrobial Activities of Calliandra surinamensis (Wall.). J. Pharmacog. Phytochem. 1, 45-50.

Subramanian, G., Meyyanathan, S. N., Karthik, Y., Karunakaranair, A. and Palanisamy, D. S. 2014. Development and validation of HPLC method for the simultaneous estimation of quercetin and rutin in Aganosma dichotoma (Roth) K. Schum. Int. J. Pharm. Pharm. Sci. 6, 606-608.
VanWagenen, B. C., Larsen, R., Cardellina, J. H., Randazzo, D., Lidert, Z. C. and Swithenbank, C. 1993. Ulosantoin, a potent insecticide from the sponge Ulosa ruetzleri. J. Org. Chem. 58, 335-337.

Wilson, J. T. and Chaikof, E. L. 2008. Thrombosis and inflammation in intraportal islet transplantation: a review of pathophysiology and emerging therapeutics. J. Diabetes Sci. Technol. 2, 746-759. 